\title{
Reservations for Women in Kerala's Local Self-government Institutions: A Mere Tokenism?
}

\author{
Navaneeth M S * \\ msnavu@gmail.com
}

May 2020

\begin{abstract}
Working Paper
Abstract

Kerala is one of the many states in India which allow 50 per cent reservation for women in local self-governance through the Panchayati Raj act of 2005 and hence the representation of women in the same has risen to almost 54 per cent, as of 2015. However the same is not reflected in the upper levels of governance namely state legislature and parliamentary elections despite Kerala being praised as a forerunner of women empowerment in India. The current state legislature has a mere 8 female members out of 141, which was almost the same since the first assembly which had 7 women members. Not to mention the state also send only one member to the Parliament, a numerical trend which has been consistent since 1950. Through this article, I would be examining whether women members of various local self-government bodies (Panchayat, Municipality etc.) have the same agency as that of a man and what are the factors and conditions preventing her from achieving the same
\end{abstract}

Keywords: Women in government, Kerala, Reservations in India, Panchayati Raj

JEL Classification: O35, O38

*Department of Humanities and Social Sciences, IIT Madras 


\section{Introduction}

The southern coastal state of India has an impressive statistics to show in terms of gender-based human development with a female literacy rate of 93 per cent (the national average is 65 per cent), fertility rate of 1.7 (the national average is 2.3), infant mortality rate of 12 (the national average is 38 ) and a healthy sex ratio of 1084 per 1000 males (the national average is 943 per 1000 males). This data is impressive for any region in South Asia, not to mention it parallels to that of East European nations. However, even with this impressive progress, women have not come to the forefront of public life or political struggle in accordance with their education and mobility. While the Kerala legislative assembly has 8 women members, in striking contrast, Haryana, a state which is known for its skewed sex ratio had 13 women in its 90 member legislative assembly, showing that there is a huge gap in the social status of women and the corresponding power they command

\section{Patriarchal Notions Dominating the Society}

The Kerala society continues to be a patriarchal one, despite having matrilineal traditions. Strictly speaking, the patriarchal system does not have any opposition to women entering the political sphere but are against the disruption in the status quo. The politics of the state continue to be a masculine affair with heavy feudal tendencies [Ameerudheen, 2017]. The women representatives are given the 'honorary' status of masculinity and the increased participation in elections does not reflect in an equivalent number of winning the same, showing how women are allocated regions having low probability of winning or rival strongholds, just to fulfil the specific number of seats needed to be set aside by the political party in order to show its social commitment. Take the recent example of the Mayor of Cochin Corporation, Soumin Jain, who was criticised for the slow-moving projects in the city because of her lack of 'strong will' or her 'feminine' approach, an accusation that will never arise against a male representative 
Historically speaking, the Syrian Christians were the first community in Kerala to adopt modern educational facilities. The Syrian Christian women were the first to avail general opportunities in educational, professional and technical sectors like that of a nurse, school teacher etc. The community was seen as a reference group by the rest of Kerala and more women started treading the same path. Not to mention the Church had an idealistic view of women as a devoted mother, wife or a daughter which was equally emulated by the Hindu upper castes. Thus women were ascribed certain roles and were expected to stay within that and ask nothing more [Mathew, 1995]

Again, all-female representatives suffer from the double burden of maintaining political life with that of one inside the house. Many of the women representatives face the danger of character assassination being used by political opponents, a tool rarely effective against a male representative, which is heavily damaging to her personal life and other commitments. Many voters still see an assertive woman as undeserving to represent them since she has an antagonising attitude which is against the accepted notions of an 'ideal' women.

Even in the popular media, the idea of how women should engage is reinforced. The women of the state being literate, are avid readers of weekly and monthly magazines. Content analysis of popular women weeklies which sell millions of copies reveals that much of the space is devoted to cookery, home decoration, child nursing, hospitality, astrology, beauty aids, gardening and kitchen garden, psychology, how to deal with members in the family and so on. The most popular women's weekly in Malayalam has set apart 42 per cent space for advertisement, all for glamorous ones, and another weekly has devoted 35 per cent for the same [Vinayan and Raj, 2019] 


\section{Low political involvement at the grass-root level}

It should not be surprising that women have a very low participation rate in the politics of the state. Although they form the bulk of teaching staff in the state, the teacher's political associations which are instrumental in securing their rights and workplace reforms, are in a weak position to influence any government level decision. The same is the state of affairs in the nursing field, where the workers are exploited in various ways from long working hours to low pay scale as well as differential treatment based on their gender. The non- gazetted officers Union, the leading political organisation in the state government machinery had only one woman president to date, although females constitute 40 per cent of the workforce. Again, CPI (M), the leading political party in the state, have only 25 per cent of members as women in spite of the party claiming to be in front of securing rights of the subaltern [Sujith, 2017]. Because of this huge gap in the political scenario, the reservation system merely tries to push women into a completely inexperienced domain, where they are under the control of various mentors from both political and familial circles with a similar disparity to the grass-root level of the constituency they represent. The women are faced with the burden of a huge learning curve not to mention the governance level of the constituency they represent also takes a hit which can be easily used for political gains by various interest.

\section{Women as proxies?}

According to the survey by Centre for Development Studies, Thiruvananthapuram, conducted within a diverse pool of women representatives across the state, about 20 per cent had a college degree. About 44 per cent of the representatives got their financial support from the political parties while about 40 per cent found the same in friends or immediate community circles. Again, against the commonly held view that it is the women of high affluent families or classes who engage in political activities, the survey showed that 
the vast majority of the women representatives came from a poor or middle-class background. Half of the women are housewives or held other informal jobs which did not supplement much of the family income [Chowdhary and Radha, 2002]. This data gives a general idea that in the case of several women, the family or party run the show with women standing as mere proxies. A very striking example of this trend was seen in the 2015 elections to the local self-governing institutions, where the women candidates in Manjeri municipality and Kuravambalam panchayat did not have their pictures in the campaigning posters and were addressed in the name of their husbands and the main leader of the respective political party. Again implementing reservation policies does not change the ground realities overnight. Although there is a surge in the power a woman would command, her property relations remain unchanged and based on the existing relations, her decisions would always be influenced by the men in her family [DN, 1989]. The survey showed that 70 per cent of the women representatives had no interest in taking up the issues affecting the womenfolk like dowry, domestic violence or alcoholism as it irked the men in the constituency. Also, women are divided among caste and class lines with this dichotomy playing an important role in deciding how the presence of women in the lowest tier of governance impact the problems faced by the women of the constituency. Almost three-fifth of the women surveyed said they would not seek for re-election due to the heavy repressive stance they faced from the political circles and due to familial obligations.

\section{Faults in the Current Policy}

The present system allows a rotation component of the seats every five years. The opportunity given by reservations in panchayats allows for leadership development but its effectiveness is being hampered in the form of rotation of reservations and particularly the mandatory rotation in the chairpersons' positions. The rotation affects the performance of the women representatives and proves an obstacle when they have to go back to their constituents asking for votes based on their performance [Buch, 2009]. Seldom does 
the same women get appointed as the nominee once the reservation criteria are taken from a constituency and this severely disables her from continuing on the existing schemes and plans devised during her term. Studies have shown that withdrawal of the reservation criteria has dissuaded 39 per cent of women representatives from seeking re-election. This points to the need to rethink the system of rotating seats reserved for women so that they are given 10 to 15 years of continued opportunity [Tiwari, 2009]. Although there is no report of gender-based discrimination by people, many representatives complain they feel inexperienced in dealing with the matters as they are new to the field and says it is unfair to compare them with the male counterparts who had been in the system for years. This inexperience also prevents her from contesting or being considered for the elections in higher levels, namely the state assembly which is evident considering Kerala has only 8 women members in the legislature. Again, seldom can a woman think of taking politics as a career unlike men and most tries to manage it with an additional job for supplementary income.

\section{The Conundrum of Experience}

Most of the elected women suffer from mishandling the administration due to their relative inexperience which affects their political career. There's a higher chance that the newly arriving women candidates are encouraged by their spouse and are relatively younger than their male counterparts [Ban and Rao, 2008] . They often rely on a political mentor who helps them to climb up the political ladder as well as understand the system and hence are influenced by them in making various decisions. The women also find the bureaucratic system, something they have to deal daily, to be unfriendly and confusing. The women complain that "The male panchayat members are closer to the officers, they can go off and have a drink or smoke" and hence the ignorance of the rules and norms are a major hindrance to them [Devika, 2012] . Again, Kerala is not a society that promotes nightlife and women always finds it unsafe to step outside alone at night which places them at a major disadvantage as a public official. She has to rely on an immediate male 
relative or a political companion which makes her slow to respond to various needs that arises. The popular lexicon for women active in politics in Kerala is that of a 'development worker' showing how people disregard women as an active component in the political culture.

However, one cannot claim all things to be in a gloomy state. The advent of Kudumbasree as a popular self-help group (SHG) has led to the mass mobilisation of women, independent of political affiliation. A lot of women in the present-day panchayat institutions have their origins in Kudumbasree and they are graded to be better experienced and performing very well in comparison with their male counterparts [Biju and Kumar, 2013].Not to mention they have a grass-root level networking and have far great social outreach among women than anyone else.

\section{Problems Faced by Dalit Women Leaders}

The Dalit women representatives of the state face double discrimination. The illustrious women leaders in the mainstream belong mostly to the dominant communities of Nair, Ezhava or Syrian Christian. The decentralised approach means that leadership positions, like that of a Panchayat president, are supposed to be 'neutral' and representing 'general' interest. Hence they have to serve the interests of their communities as well as the panchayat which could often cause conflicts with officials and sections of the population, especially when it came to spending funds earmarked for Scheduled Castes and Tribes. They are often accused of standing on behalf of the Dalit community and not the whole panchayat. Again, Dalit political mobilisation is very low in Kerala and the members are often brushed aside by mainstream parties with their role limited to the lower ranks [Devika, 2012].

The status of Dalit women also presented two models of disempowerment. One way was that she was completely embedded in her local party which insisted that all decisions were taken in and through 
the party, and she had little more to contribute. These women often viewed the party like a family which is there to meet all their needs. The other way was that she was disadvantaged by her relatively poor educational levels, lack of connections and working-class status. This made her prone to latent violence from both the sides: the ruling side, to which she belonged, which wanted to keep her in check and the opposition which was waiting to catch on any of her misdoings for political leverage [Devika and Thampi, 2012]

\section{Fear and Scepticism with Empowerment}

The state's society still views opinionated women to be outspoken, arrogant, male-bashers and labels them with colloquial terms that can be loosely associated with that the notion of 'pseudo-feminism'. A woman representative is expected to be a torch-bearer of the 'ideal' form of a Malayali woman and is expected to exercise 'gentle' power which is considered as a feminine quality and similar to the one she exercises back home, subordinate to male power and negotiating in nature.

There exist sceptics in the society, who consider greater participation of women or their representation in politics through reservations to be, at best, symbolic. Successful middle or upper-class women holding stable government or corporate jobs are the most articulate proponents of this view. Their arguments amount to the following: "Look at us. We have succeeded in the men's world without any quota. So why do women need a quota to be successful in politics?" This argument is similar to those who use the 'merit' argument to oppose any positive discrimination. There also exist several successful Dalit or OBC professionals who oppose reservations, by confusing their own subjective experience with the general conditions, which may have been marked by privileges or sheer good luck. But, in the case of those successful women opposing reservation for women in legislatures, they seem to believe that a display of cynicism towards the political process and insensitivity towards gender discrimination reflects virtuosity. Being a professionally successful woman in a world dominated by men 
is certainly commendable, but that does not automatically make someone gender-sensitive or aware of the problems and concerns of women, especially of those in lower strata. Women active in politics, almost without exception and cutting across political affiliations, are supporters of women's reservation because their own experience has shown them the enormous difficulty in sustaining political activism and competing with men successfully in a patriarchal setting [Bose, 2010].

\section{Concluding Notes}

There exist several hindrances for the upward mobility of women in the political ladder of the state in spite of the huge improvements the state has made in other aspects of women's welfare. The structural inequality existing in the society due to economic and social factors contradicts the popular narrative that portrays the state as 'egalitarian' and 'progressive'. Again many instances show how caste continues to play an important role in the politics of the state which it has tried to mask in many ways. However, the reservation policies sure have their share of positive impacts despite the flaws. The state has actively implemented the National Perspective Plan for Women (1988) and has allocated a large control of local funds to the representatives in the lowest tier, meaning women representatives can implement a lot of their visions without interference from the top. Most of the newly elected women are shown to study as well as comprehend the government machinery within the first 7 months and the people perceive women representatives to be more approachable, enthusiastic and less corrupt. The women representatives of Kerala are measured to be best performing representatives in all of India which shows that their trajectory is in the right direction 


\section{References}

[Ameerudheen, 2017] Ameerudheen, T. (2017). Women have a large presence in kerala's local government bodies, but it's often men who run the show. Scroll.in.

[Ban and Rao, 2008] Ban, R. and Rao, V. (2008). Tokenism or agency? the impact of women's reservations on village democracies in south india. Economic Development and Cultural Change, 56(3):501-530.

[Biju and Kumar, 2013] Biju, B. L. and Kumar, K. G. A. (2013). Class feminism: The kudumbashree agitation in kerala. Economic and Political Weekly, 48(9):22-26.

[Bose, 2010] Bose, P. (2010). Women's reservation in legislatures: A defence. Economic and Political Weekly, 45(14):10-12.

[Buch, 2009] Buch, N. (2009). Reservation for women in panchayats: A sop in disguise? Economic and Political Weekly, 44(40):8-10.

[Chowdhary and Radha, 2002] Chowdhary, B. R. and Radha, S. (2002). Women in Local Bodies. Technical Report 22, Centre For Development Studies.

[Devika, 2012] Devika, J. (2012). Rockets with fire in their tails? women leaders in kerala's panchayats. India International Centre Quarterly, $39(3 / 4): 42-53$.

[Devika and Thampi, 2012] Devika, J. and Thampi, B. V. (2012). Beyond feminine public altruism: Women leaders in kerala's urban bodies. Economic and Political Weekly, 47(17):76-83.

[DN, 1989] DN (1989). Reservations for women in panchayats. Economic and Political Weekly, 24(23):1269-1270.

[Mathew, 1995] Mathew, G. (1995). The paradox of kerala women's social development and social leadership. India International Centre Quarterly, $22(2 / 3): 203-214$.

[Sujith, 2017] Sujith, N. (2017). Cpm is changing. so are its challenges. OnManorama. 
[Tiwari, 2009] Tiwari, N. (2009). Rethinking the rotation term of reservation in panchayats. Economic and Political Weekly, 44(5):23-25.

[Vinayan and Raj, 2019] Vinayan, S. and Raj, M. S. (2019). The politics of representation and the "ideal malayalee woman": Remembering malayalam women's magazines of the early 20th-century kerala, south india. Journal of Postcolonial Writing, 55(3):399-411. 